\title{
ROLE OF CONVENTIONAL ADS IN A DIGITAL AGE: EFFECTS OF INTERNET AND CONVENTIONAL ADVERTISING ON BRAND AWARENESS AND BRAND DESIRE IN CHINA
}

\author{
Terri H. Chan \\ Hong Kong Baptist University \\ Department of Communication Studies, Kowloon, Hong Kong \\ terrichan@hkbu.edu.hk \\ Fine F. Leung \\ The University of Hong Kong \\ School of Business, Pokfulam Road, Hong Kong \\ fleung@business.hku.hk \\ Peking Tan \\ Millward Brown \\ No.3, Xinyuan South Road, Chaoyang District, Beijing \\ peking.tan@millwardbrown.com \\ David K. Tse \\ The University of Hong Kong \\ School of Business, Pokfulam Road, Hong Kong \\ davidtse@business.hku.hk
}

\section{ABSTRACT}

In our increasingly digital era, Internet advertising efforts continue to expand with a strong ability to efficiently target, behaviorally profile, and interactively engage consumers. This trend is a challenge to conventional advertising efforts and calls into question what roles they may continue to play. This study delineates that in the digital era, Internet and conventional advertising efforts have differentiating functions in shaping consumer brand perceptions. Collating data from two independent sources, we examined 195 leading consumer brands across 23 product categories in China in 2011 to verify our key postulates. The findings confirmed the salience of both Internet and conventional advertising efforts on generating brand awareness, and uncovered the unique role of conventional advertising efforts in directly creating brand desire. Furthermore, the effect of conventional advertising efforts on brand desire is contingent on the nature of whether the consumer 
brands are hedonic or utilitarian.

Keywords: Internet Advertising, Conventional Advertising, Brand Awareness, Brand Desire, Consumer Product Brands in China

\section{INTRODUCTION}

The explosive success of new media (via the Internet) as an advertising medium is forcing firms to rethink how they can better connect to and interact with their consumers. While some brand managers view the Internet as a reflective platform for sourcing consumer insights ${ }^{1,2}$, others regard it as a cost-efficient advertising medium ${ }^{3,4}$. In China, evidence indicates that some brand managers take a bolder approach towards the new media and use it to structurally revise their communication mix ${ }^{5}$. Through successful campaigns, these brands have established themselves as new media leaders. They have attracted intense interest among marketing professionals and turned Internet advertising into one of the most dynamic marketing topics. Indeed, Millward Brown's 2010 survey reports that $96 \%$ of members in the World Federation of Advertisers increased their efforts in social media. Yet among them, $50 \%$ are uncertain about the return on investments and only a few firms have clearly defined their new media strategies ${ }^{6}$. Most firms hold eager yet uncertain attitudes because the role of the Internet versus conventional media remains unclear. Our study attempts to fill this research gap by investigating how Internet and conventional advertising efforts affect consumer brand awareness and desire. We developed and empirically tested a model that assesses their differential effects. In addition, we also examined how product nature, that is, whether the brand is designed for hedonic or utilitarian functions, may affect the advertising effect on brand desire.

\section{PROPOSED MODEL AND HYPOTHESES}

One of the major goals of advertising, Internet and conventional alike, is to generate and maintain brand awareness. In this study, brand awareness is defined as consumers' unaided first-mention brand recall within each product category ${ }^{7}$. Previous literature supports that both Internet and conventional advertising efforts contribute to brand awareness and increase the probability that the brand is included in the consumer's evoked set ${ }^{8,9}$.

Emerging literature on new media establishes that Internet advertising is salient in affecting brand awareness ${ }^{3,4}$. First, Internet advertising content can be highly relevant to consumers. Using sophisticated data sourcing and analytical tools, consumer sentiments and behaviors posted on various web platforms (from web communities to social media) are made available to firms that can design advertisements to ride on the "right here, right now" 
needs of consumers. Furthermore, through in-house customer databases and profiling systems, firms can sub-segment their existing customer groups and design advertisements and promotions that correspond to their consumption patterns. Second, firms can create brand awareness by creating buzz online. Through viral messages and advertisements, Internet advertising can expand brand awareness by engaging consumers and creating positive word-of-mouth ${ }^{10,11}$.

Frequent exposure to a brand via conventional advertising can escalate the brand's salience, thereby increasing consumers' ability to recall the brand $^{12}$. Repeatedly viewing a brand's television or magazine advertisements, for example, would reinforce the linkage between the brand and consumers' category needs. At the same time, conventional advertising offers unrivaled reach. Among the over 400 television channels in China, the state broadcaster China Central Television (CCTV) operates 20 channels and has an audience of 1.2 billion or over $95 \%$ of the country's total population ${ }^{13}$. High visibility and the exposure of conventional advertising builds brand awareness by planting brand impressions at numerous consumer touch-points. Thus, we hypothesize that:

H1a: Internet ad expenses have a positive effect on brand awareness.

H1b: Conventional ad expenses have a positive effect on brand awareness.

Another major goal of advertising is to create brand desire, defined as consumer's sense of longing and wanting for the brand. This reflects the higher-arousal, hotter aspects of brand love frequently called passion ${ }^{14}$. This study proposes three different characteristics between Internet and conventional advertising that may impact their relative effect on building brand desire: (1) capacity for emotional content, (2) perceived ad clutter, and (3) consumer goal-orientation. First, Internet and conventional advertising may differ in their capacity to stimulate emotional responses. Internet advertising (e.g., banner ads) is often bounded by screen space and streaming technology. As such, their creative contents are limited relative to those in conventional media. Appealing sound and visual effects, emotion-rich narratives, and large screen sizes of conventional advertising (e.g., TV ads) empower brands to be innovative in designing creatives. Therefore, conventional advertising may possess a greater capacity to elicit emotional engagement from consumers ${ }^{15}$. In fact, Heath, Brandt, and Nairn ${ }^{16}$ demonstrate that it is an advertisement's emotional content, not its rational message, that shifts brand preference and desire.

Second, Internet and conventional advertising may differ in perceived ad clutter ${ }^{17}$. Conventional advertising is sequentially presented, shown one advertisement at a time while Internet allows multiple advertisements (e.g., search ads) to appear simultaneously on the same screen. This 
over-crowding effect resembles excessive advertisements and may irritate consumers, making it difficult for Internet advertising to build brand desire directly. In contrast, most advertisements are filtered qualitatively with the targeted audience in mind, thus ads on conventional media are readily accepted by viewers. Lastly, consumers approach the Internet and conventional media with different goal-orientations. Consumers who surf the Internet for particular purposes are task-oriented, hence irrelevant advertisements are perceived as nuisances and often ignored. In contrast, consumers generally approach conventional media (e.g., TV, radio) for entertainment purposes. As such, narratives formed by conventional advertising can induce transportation ${ }^{18,19}$. According to Green and Brock's ${ }^{20}$ transportation theory, transported consumers are immersed into the narratives and feel as though the narrative experiences were real. Their negative cognitive response is reduced and they are less likely to counter-argue advertising claims. In sum, we suggest that relative to Internet advertising, conventional advertising possesses higher emotional content, less ad clutter, and a higher chance to induce narrative transportation that positively affects consumer brand desire. Thus, we hypothesize that:

H2a:Internet ad expenses have a positive effect on brand desire, and its effect is fully mediated by brand awareness.

$\mathrm{H} 2 \mathrm{~b}$ : Conventional ad expenses have a positive effect on brand desire, and its effect is partially mediated by brand awareness.

This study also attempts to explore whether the role of conventional advertising efforts in building brand desire may differ between product types. Utilitarian products are consumed for their functional benefits, while hedonic products are consumed for the pleasure derived from the consumption experience $^{21}$. Just a decade ago, Chinese consumers were novices in the world of consumption, and they overwhelmingly sought basic functional benefits in their products ${ }^{22}$. Therefore, the consumption of utilitarian products (e.g., cooking oil, instant foods) in China is more mature and these traditional categories are often dominated by local brands ${ }^{23}$. According to Bain's China Shopper Report in 2012, many local brands in utilitarian categories are trying to improve their brand image by entering the high-end segments. Thus, they are more likely to use conventional advertising as a tool to directly boost their brand image and ultimately create consumer desire.

In contrast, riding on the consumerism era and increasing sophistication of Chinese consumers, hedonic products (e.g., apparel, wine) have gained high traction in recent years. A population characterized by rising disposable income and rapid urbanization has attracted numerous foreign brands to enter China, turning the marketplace into a fiercely 
competitive playing field. To establish a stronger foothold, brands in hedonic categories are more likely to utilize conventional advertising's high exposure and reach to boost brand awareness, and its effect on directly influencing brand desire may be weakened. In sum, we postulate that:

H3a: Conventional ad expenses have a positive effect on brand desire, and its effect is partially mediated by brand awareness for utilitarian products. H3b: Conventional ad expenses have a positive effect on brand desire, and its effect is fully mediated by brand awareness for hedonic products.

Our conceptual model is shown in Figure 1. We conducted a brand-level study using secondary data from two independent sources to test our hypotheses.

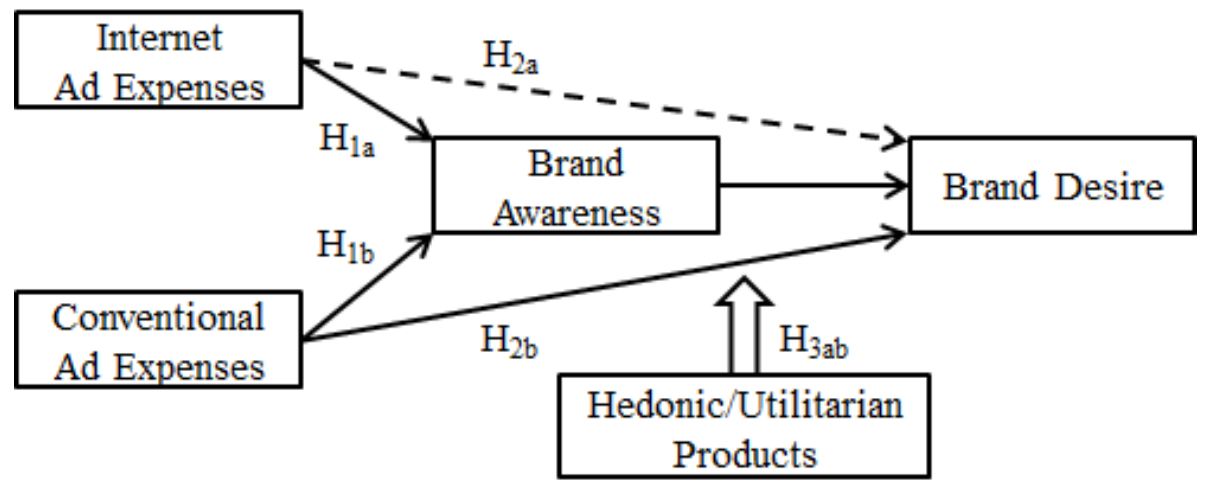

Figure 1. Conceptual model

\section{STUDY CONTEXT AND DATA COLLECTION}

Our study included 195 consumer brands across 23 product categories in China in 2011. We collated secondary data from two independent sources. Internet and conventional advertising expenses data were obtained from GroupM, one of the largest media buyers globally. Brand measures, including brand awareness, brand desire, and brand age, were collected from BrandZ by Millward Brown, a global brand research conglomerate. The two-source design helped to reduce common method biases.

We used brand as the level of analysis. Actual advertising expenses were used as proxies for a brand's devoted efforts to Internet and conventional advertising. Internet ad expenses included marketer-generated spending on websites, social networks, display ads, and search ads; conventional ad expenses included advertising spending on television, print, and radio. Individual consumer responses on brand awareness and brand desire were collected through Millward Brown's online consumer panel in China. On average, 220 consumer responses were collected for each brand. 
Consumer responses were then aggregated to brand-level scores using Millward Brown's proprietary method. Brand awareness was operationalized as a brand's score on unaided first-mention recall within each product category, and brand desire was the extent to which respondents found the brand "desirable". Brand age was the number of years the brand has existed in China, and it was used as a control variable on both brand awareness and brand desire. We further assigned the brands based on local $(N=102)$ or foreign $(N=93)$ origin and used it as a control variable on brand desire. To test our hypotheses, path analysis was conducted using AMOS and results were validated using mediation analyses.

\section{ANALYSIS AND RESULTS}

Using maximum likelihood estimation, the path analysis test indicated that the data fit our hypothesized model very well $\left(\chi^{2}(1)=.009, p>.05\right.$; NFI $\approx 1$; CFI $\approx 1$; RMSEA $\approx 0$ ). Whether a brand is of local or foreign origin had no significant effect on brand desire $(\beta=.070, p>.05)$, and brand age had no effect on both brand awareness $(\beta=-.016, p>.05)$ and desire $(\beta=.103$, $p>.05)$. The path diagram is shown in Figure 2 and the results supported our hypotheses. Internet ad expenses had a positive effect on brand awareness $(\beta=.261, p<.001)$, but no significant effect on brand desire $(\beta=$ $-.049, p>.05)$. Brand awareness showed a strong effect on brand desire $(\beta$ $=.675, p<.001$ ), which signified that the effect of Internet ad expenses on brand desire might be mediated by brand awareness. In contrast, conventional ad expenses showed positive effects on both brand awareness $(\beta=.194, p<.01)$ and desire $(\beta=.134, p<.05)$.

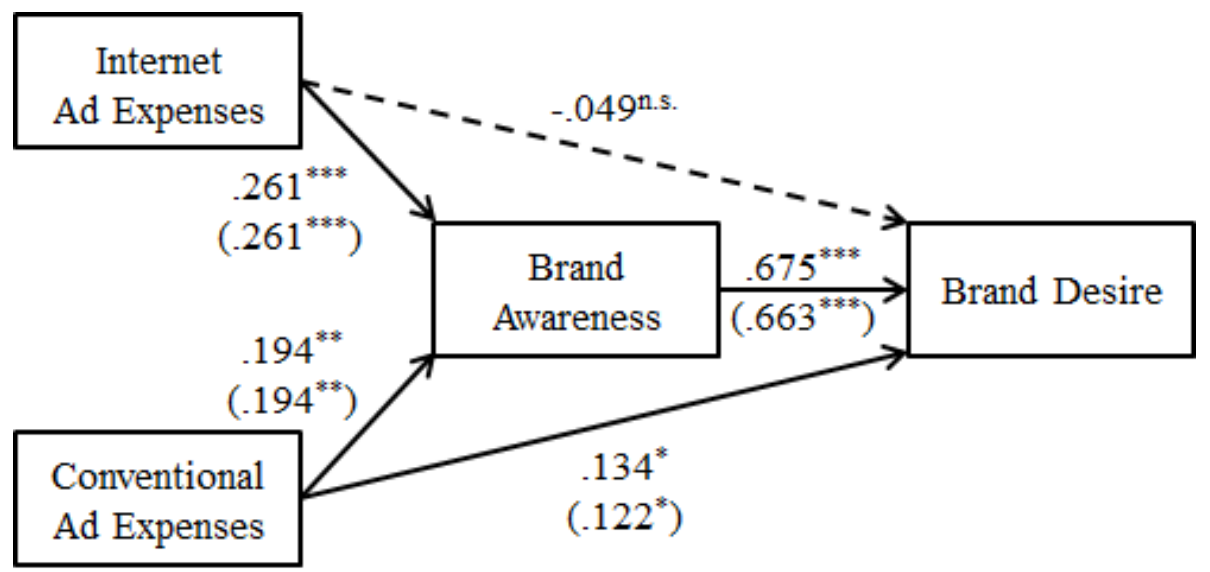

Notes: Standardized path coefficients of the hypothesized model are shown here; path coefficients of the trimmed model are shown in parentheses. Significance levels are denoted by ${ }^{*}$ at $p \leq .05 ;{ }^{* *}$ at $p \leq .01 ;{ }^{* * *}$ at $p \leq .001 ;$ n.s. $=\operatorname{not}$ significant.

Figure 2. Path diagram of the hypothesized and trimmed models 
In the trimmed model, the non-significant path between Internet ad expenses and brand desire was removed. The trimmed model fit the data very well $\left(\chi^{2}(2)=.839, p>.05\right.$; NFI $=.997$; CFI $\approx 1$; RMSEA $\left.\approx 0\right)$. There was no significant improvement in the model fit with the additional non-significant path between Internet ad expenses and brand desire $\left(\Delta \chi^{2}(1)\right.$ $=.830, p>.05)$.

A. Internet ad expenses on brand desire

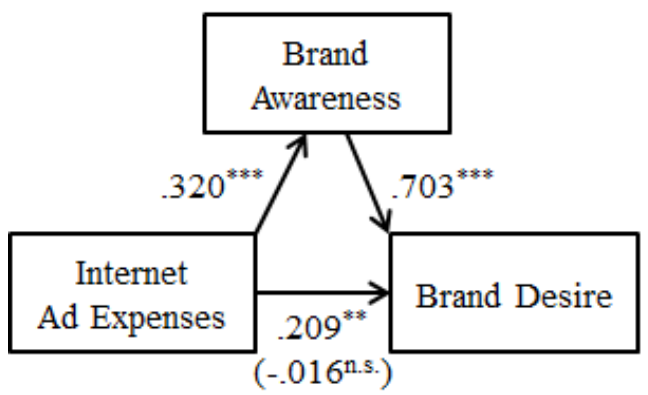

B. Conventional ad expenses on brand desire

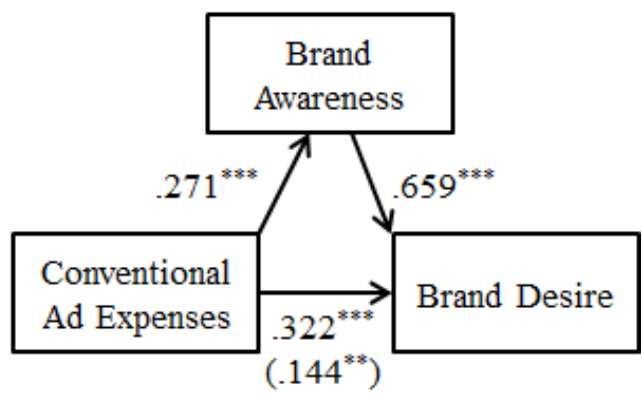

Notes: Standardized regression coefficients are shown here. Significance levels are denoted by ${ }^{*}$ at $p \leq .05 ;{ }^{* *}$ at $p \leq .01 ;{ }^{* * *}$ at $p \leq .001 ;$ n.s. $=$ not significant. Results in parentheses indicate the effects when both the independent variables and brand awareness were used to predict brand desire.

Figure 3. Mediation effects of brand awareness

To further confirm the mediation effects of brand awareness, we ran mediation analyses following Baron and Kenny's ${ }^{24}$ procedures. The results revealed that the effect of Internet ad expenses on brand desire was fully mediated by brand awareness, while the effect of conventional ad expenses on brand desire was partially mediated by brand awareness (see Figure 3).

We also tested the role of conventional advertising in affecting brand desire for different product types. We assigned the brands based on a hedonic $(N=100)$ or utilitarian $(N=95)$ function for each product category. Results from mediation analyses supported our hypotheses. The effect of conventional ad expenses on brand desire was fully mediated by brand awareness for hedonic products and partially mediated by brand awareness for utilitarian products (see Figure 4). The results indicated the unique role of conventional advertising efforts in directly inducing consumer brand desire, particularly for utilitarian products. 
A. Hedonic Products

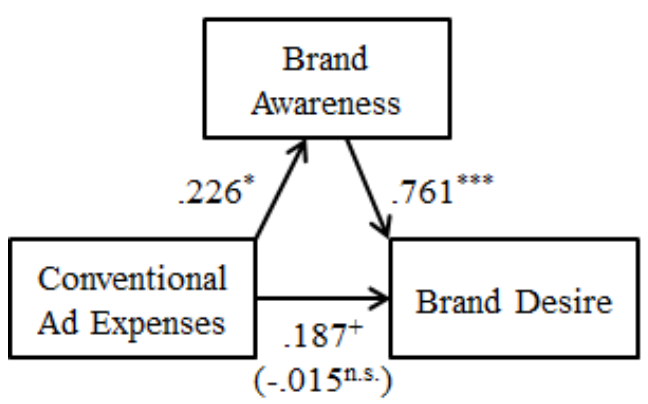

B. Utilitarian Products

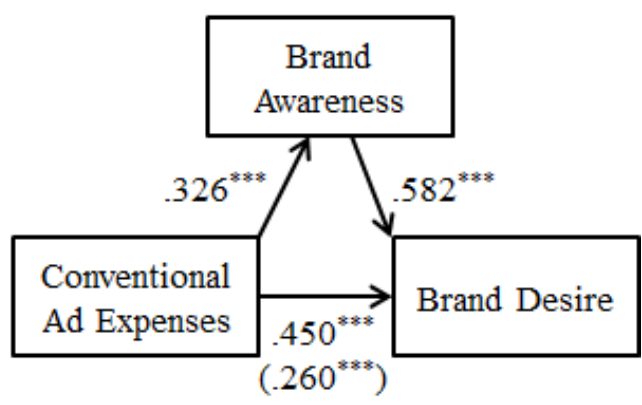

Notes: Standardized regression coefficients are shown here. Significance levels are denoted by ${ }^{+}$at $p \leq .10 ;{ }^{*}$ at $p \leq .05 ;{ }^{* *}$ at $p \leq .01 ;{ }^{* * *}$ at $p \leq .001 ; n . s .=$ not significant. Results in parentheses indicate the effects when both conventional ad expenses and brand awareness were used to predict brand desire.

Figure 4. Mediation effects of brand awareness on different product types

\section{DISCUSSION AND SUMMARY}

This study provided interesting results on the respective roles played by the Internet and conventional advertising efforts in our increasingly digital era. As documented in several research studies and anecdotal cases that emphasize the effects of Internet advertising, our results reveal that Internet advertising is indeed an important marketing tool in boosting brand awareness. Yet, Internet advertising may not have a direct effect on building brand desire; rather its effect may be fully mediated by brand awareness. Our findings suggest that while there is a strong push for greater advertising efforts in the new media, the limits of its effects need to be recognized. In contrast, conventional advertising efforts are shown to be instrumental in stimulating both brand awareness and desire. Our findings suggest that in today's digital era, conventional advertising efforts continue to have a unique role to play in directly creating consumer brand desire, particularly for utilitarian products in China.

This paper provided two research contributions. First, it delineated and validated the salience of the respective effects of new and conventional media. Second, it offered empirical support regarding the respective roles they provide. At a time when many researchers are focusing on new media effects, this study sheds light on the unique roles that conventional advertising may play in creating consumer brand desire.

Several limitations to our study suggest further research opportunities. First, the Internet and conventional ad expenses used in our study include various types of channels. It may be worthwhile to investigate the effects of specific channels (e.g., television vs. display ads) to further isolate the 
effects. Second, although we proposed three different characteristics between Internet and conventional advertising that may impact their relative effects on brand desire (i.e., capacity for emotional content, perceived ad clutter, and consumer goal-orientation), the underlying mechanisms were not tested in our study. Experiments can be conducted in the future to validate our postulates.

Our study provides a number of managerial implications. First, it supports the current dual-media approach that most brands adopt. By spreading advertising efforts across the two types of media, marketers are able to effectively strategize their budget for higher performance. Second, our findings point to the distinctive roles that new and conventional media efforts play. Accordingly, it suggests marketing managers to be more prudent in defining their advertising objectives and augmenting their advertising budget. It is important to point out that our findings do not imply that conventional media would remain intact in the future. While the findings do not support the radical notion that all future advertising efforts will inevitably be digital, the media world is rapidly changing. In fact, the boundaries between new and conventional media are blurring. With continuous advancements in web-surfing and broadcasting technology, the creative and entertainment edges that conventional media enjoy over new media may soon disappear. By then, conventional advertising may face a formidable challenge. In China, however, conventional media remains an important avenue to acquire information and seek entertainment. Television watching, in particular, is a familial activity integral to the Chinese culture. This suggests that in China, conventional advertising will endure its importance in the communication mix and is unlikely to be disrupted in the near future.

\section{ACKNOWLEDGE}

This study is supported by a General Research Grant by the Hong Kong SAR Government (HKU 7539110H).

\section{REFERENCES}

[1] D. Godes and D. Mayzlin, Using online conversations to study word-of-mouth communication. Marketing Science, 23(4), p545-560, 2004. http://dx.doi.org/10.1287/mksc.1040.0071.

[2] F.Y. Wang, K.M. Carley, D. Zeng and W. Mao, Social computing: From social informatics to social intelligence. IEEE Intelligent Systems, 22(2), p79-83, 2007. http://dx.doi.org/10.1109/MIS.2007.41.

[3] J.A. Chevalier and D. Mayzlin, The effect of word of mouth on sales: Online book reviews. Journal of Marketing Research, 43(4), p345-354, 
2006.

[4] F. Zhu and X. Zhang, Impact of online consumer reviews on sales: The moderating role of product and consumer characteristics. Journal of Marketing, 74(2), p133-148, 2010. http://dx.doi.org/10.1509/jmkg.74.2.133.

[5] Does your brand need social media and brand fans? Millward brown knowledge points. Retrieved on September 8, 2013, from http://www.millwardbrown.com/docs/default-source/insight-documents /articles-and-reports/2011_FanZ_Social_Media_and_Brand_Fans.pdf.

[6] J. Bughin, A.H. Byers and M. Chui, How social technologies are extending the organization. McKinsey Quarterly, 20(11), p1-10, 2011.

[7] L. Percy and J.R. Rossiter, A model of brand awareness and brand attitude advertising strategies. Psychology \& Marketing, 9(4), p263-274, 1992. http://dx.doi.org/10.1002/mar.4220090402.

[8] C.J. Cobb-Walgren, C.A. Ruble, and N. Donthu, Brand equity, brand preference, and purchase intent. Journal of Advertising, 24(3), p25-40, 1995. http://dx.doi.org/10.1080/00913367.1995.10673481.

[9] X. Dreze and F.X. Hussherr, Internet advertising: Is anybody watching? Journal of Interactive Marketing, 17(4), p8-23, 2003. http://dx.doi.org/10.1002/dir.10063.

[10] A.M. Kaplan and M. Haenlein, Users of the world, unite! The challenges and opportunities of social media. Business Horizons, 53(1), p59-68, 2010. http://dx.doi.org/10.1016/j.bushor.2009.09.003.

[11] D.M. Scott, The new rules of marketing and PR: How to use news release, blogs, podcasting, viral marketing and online media to reach buyers directly. Hoboken, NJ: John Wiley \& Sons, 2007.

[12] J.W. Alba and A. Chattopadhyay, Salience effects in brand recall. Journal of Marketing Research, 23(4), p363-369, 1986. http://dx.doi.org/10.2307/3151812.

[13] N. Twizell, CCTV, 1.2 billion viewers strong. The Review of Creative Industries and Media. Retrieved on September 8, 2013, from http://www.inaglobal.fr/en/television/article/cctv-12-billion-viewers-str ong.

[14] R. Batra, A. Ahuvia and R.P. Bagozzi, Brand love. Journal of Marketing, 76(2), p1-16, 2012. http://dx.doi.org/10.1509/jm.09.0339.

[15] R. Heath, Emotional engagement: How television builds big brands at low attention. Journal of Advertising Research, 49(1), p62-73, 2009. http://dx.doi.org/10.2501/S0021849909090060.

[16] R. Heath, D. Brandt, and A. Nairn, Brand relationships: Strengthened by emotion, weakened by attention. Journal of Advertising Research, 46(4), p410-419, 2006. http://dx.doi.org/10.2501/S002184990606048X.

[17] C.H. Cho and H.J. Cheon, Why do people avoid advertising on the 
internet? Journal of Advertising, 33(4), p89-97, 2004. http://dx.doi.org/10.1080/00913367.2004.10639175.

[18] B.J. Phillips and E.F. McQuarrie, Narrative and persuasion in fashion advertising. Journal of Consumer Research, 37(3), p368-392, 2010. http://dx.doi.org/10.1086/653087.

[19] J.E. Escalas, Self-referencing and persuasion: Narrative transportation versus analytical elaboration. Journal of Consumer Research, 33(4), p421-429, 2007. http://dx.doi.org/10.1086/510216.

[20] M.C. Green and T.C. Brock, The role of transportation in the persuasiveness of public narratives. Journal of Personality and Social Psychology, 79(5), p701-721, 2000. http://dx.doi.org/10.1037//0022-3514.79.5.701.

[21] E.C. Hirschman and M.B. Holbrook, Hedonic consumption: Emerging concepts, methods and propositions. Journal of Marketing, 46(3), p92-101, 1982. http://dx.doi.org/10.2307/1251707.

[22] Y. Atsmon, M. Magni, A. Jin and L. Li, From mass to mainstream: Keeping pace with China's rapidly changing consumers. McKinsey consumer \& shopper insights, 2012. Retrieved on September 8, 2013, from http://mckinseyonmarketingandsales.com/mass-to-mainstream.

[23] B. Lannes and M. Booker, What Chinese shoppers really do but will never tell you? Bain china shopper report, 2012. Retrieved on September 8, 2013, from http://www.bain.com/publications/articles/what-chinese-shoppers-reall y-do-but-will-never-tell-you.aspx.

[24] R.M. Baron and D.A. Kenny, The moderator-mediator variable distinction in social psychological research: Conceptual, strategic, and statistical considerations. Journal of Personality and Social Psychology, 51(6), p1173-1182, 1986. http://dx.doi.org/10.1037/0022-3514.51.6.1173. 
